\title{
Engaging Teachers and School Leaders in Participatory Data Analysis for the Development of a School-Based Mental Health Intervention
}

\author{
Ruth D. Neill ${ }^{1}$ (1) Paul Best ${ }^{1} \cdot$ Katrina Lloyd $^{1}$ - Janet Williamson ${ }^{2} \cdot$ Jack Allen $^{2} \cdot$ Jennifer Badham $^{3} \cdot$ Mark. A. Tully $^{4}$
}

Accepted: 3 February 2021 / Published online: 26 February 2021

(c) The Author(s) 2021

\begin{abstract}
The success of school-based mental health interventions is often inconsistent, in part due to lack of input from teachers and students in the programme design. Therefore, the involvement and engagement of teachers in the co-production of an intervention, especially within data analysis, can create more innovative and effective solutions. This paper presents a teacher-led qualitative data analysis using a new approach within the field, participation theme elicitation. This approach will be used to gather information relevant to the initial development of a school-based mental health intervention. Teachers identified the following themes: (1) physical activity as a stress reliever, (2) programme facilitation, (3) exam pressure and (4) solutions to improve negative mental health. Results from the teacher-led analysis are broadly similar to previous research in the field. Our findings demonstrate that teachers can have a valuable input into research findings which should help address the development of a school-based mental health intervention. In summary, the findings suggest that the use of participatory theme elicitation is a valid and effective method to address the gaps and limitations of participatory qualitative data analysis.
\end{abstract}

Keywords Teachers · Qualitative data analysis $\cdot$ Co-researchers $\cdot$ Participatory theme elicitation

\section{Introduction}

Mental health issues are the leading cause of disabilityadjusted life years in high-income countries, accounting for 16 per cent of the global burden of disease for adolescents between the ages of 10-19 years old (World Health Organisation, 2020,2019; Brown \& Dixon, 2020; Erskine et al., 2015). A number of these young people with mental health-related issues will go undetected and around 70 per

Ruth Neill and Paul Best have contributed equally to this work. Katrina Lloyd, Janet Williamson, Jack Allen, Jennifer Badham, Mark. A. Tully have contributed equally to this work.

Ruth D. Neill

rneill14@qub.ac.uk

1 School of Social Sciences, Education and Social Work, Queen's University Belfast, Belfast, Northern Ireland

2 Royal Belfast Academical Institution, Belfast, Northern Ireland

3 Durham University, Stockton Road, Durham DH1 3LE, England

4 School of Health Sciences, Institute of Mental Health Sciences, Ulster University, Jordanstown Campus, Newtownabbey, Northern Ireland cent of those detected will not receive appropriate support or treatment (Mental Health Foundation, 2020; World Health Organisation, 2019). Therefore, research suggests that early intervention may be crucial in combatting the prevalence of adolescent mental health issues (Weeks, Hill, \& Owen, 2017; Eiland \& Romeo, 2013). By creating positive attitudes around mental health and well-being from an early stage, adolescents can build the resilience they need to be able to cope with challenging situations (World Health Organisation, 2019; Brown \& Dixon, 2020; Shalanski \& Ewashen, 2019).

Interventions can be beneficial in improving mental health outcomes; therefore, the school environment has been identified as an important setting for implementing mental health-related programmes (Brown \& Dixon, 2020; Jones, West, \& Suveg, 2019; Das et al., 2016). Children and young people spend a significant proportion of their time in school as education is compulsory in the United Kingdom between the ages of 5-16 years old (Holt, Greif Green, \& Guzman, 2018; Bradshaw \& Keung, 2011; Pugh \& Statham, 2006). Therefore, the school is a universally accepted setting for an intervention as the programme can be applied to individuals regardless of gender or background and provides a continuous structured environment for introducing interventions 
to children and young people (Lakes, Nguyen, Jones, \& Schuck, 2019; Breslin \& Brennan, 2012). Additionally, it is acknowledged that schools provide an intervention setting which offers a greater likelihood of programme adherence as it can be perceived as a less threatening and more open environment in comparison with a clinical or communitybased interventions (Arnold, Bruce-Low, Henderson, \& Davies, 2016; Hoover and Mayworm, 2007).

While the school setting can facilitate the delivery of multi-component interventions (Breslin \& Brennan, 2012; Durlak, Weissberg, Dymnicki, Taylor, \& Schellinger, 2011; Mulvaney-Day, Rappaport, Alegria, \& Codianne, 2006), Pugh and Statham (2006) acknowledged that there is little evidence of the effectiveness of school mental health and well-being programmes. Additionally, many of these schoolbased interventions did not place an emphasis on mental health and well-being outcomes; instead, the programmes focused on improvements to academic outcomes, cognitive functioning or increasing the level of physical activity undertaken (Sullivan, Kuzel, Vaandering, \& Chen, 2017; Ribeiro et al., 2010).

Adolescents often have to rely on schools and teachers for their mental health education and unfortunately schools and teachers are not often provided with adequate training and resources to facilitate this (O'Reilly et al., 2018; St Leger, 2001). This was highlighted in the Time to Change report (2012) which illustrated that many teachers within the UK do not receive appropriate support or guidance to tackle mental health and well-being in schools. Similarly, NICCY (2017) acknowledged that the I-Matter programme, which was implemented in Northern Ireland to promote resilience, health and well-being, demonstrated that many schools did not feel equipped to deal with the mental health and well-being of their students. Evidence suggests that the lack of appropriate support and guidance makes it difficult for schools to implement interventions and that the success of these interventions has been inconsistent due to a lack of collaboration and input from key stakeholders (Biddle, Mutrie, \& Gorely, 2015; Time to Change, 2012). Therefore it is important to incorporate the perspectives of teachers and students into co-producing a school-based intervention. O'Donnell and Dunlap (2019) acknowledged this stating that it is critical to consider teachers' acceptability of a schoolbased intervention thus indicating that teacher input is essential within the intervention development process.

A mental health intervention for adolescents, particularly one that is designed in conjunction with schools, may help to address this issue. A crucial component is engaging stakeholders in the development of the programme (Arnold et al., 2016; Biddle et al., 2015; World Health Organisation, 2012). Co-production is a particularly useful way to involve stakeholders in the development of an intervention, and this can help to create more workable solutions
(Væggemose, Ankersen, Aagaard, \& Burau, 2018; Clarke, Jones, Harris, \& Robert, 2017; Hawkins et al., 2017). However, often within the co-production process, stakeholders are not included in all aspects of the research, particularly data analysis, as equal partners.

This article presents co-researcher (teacher) qualitative data analysis gathered during the initial development of a school-based mental health intervention. The analysed data was used to inform intervention design and delivery and to focus the target to a specific school-based mental health issue. The entire project lasted two years and was based within one school in Northern Ireland. A unique element of the work conducted in this paper is the use of Participatory Theme Elicitation (PTE) in the data analysis process. This five-step process provides a more accessible and understandable process for key lay co-researchers and academic researchers (Yap et al. 2020; Best, McConnell, Davidson, Badham, \& Neill, 2019). PTE is a relatively new approach first developed in 2017 and has shown promise in previous mental health research with youth from schools (Best et al., 2017), co-researchers from the public to examine group based video-conferencing for adults with depression (Best et al., 2019) and co-researchers to examine an exercise intervention for people with serious mental illness. Findings support PTE as an effective, accessible and valid method to use with lay-researchers, but this has yet to be tested with teachers in a school-based setting. Therefore, this paper will examine the use of PTE with teachers in the school environment.

\section{Rationale for Including Co-Researchers in Data Analysis}

Often in intervention co-production and co-design, stakeholders and research partners are not included within the data collection process and are excluded from data analysis. Research suggests that participatory data analysis has the potential to create more workable solutions for complex issues such as mental health (King \& Gillard, 2019; Troya et al. 2019; Lind, 2007). A study by Stevenson (2014) provided individuals with Down Syndrome the opportunity to be co-researchers and be involved in participatory data analysis. As part of this process, the co-researchers highlighted transcripts, made notes, and provided opinions on what information in the interview transcripts from the "Voices for Change" project they found insightful to generate themes. Stevenson (2014) noted that while using co-researchers can be valuable, data analysis can be limited due to time commitments of the co-researchers. However, evidence suggests involving stakeholders as co-researchers in the data analysis process can provide an alternative perspective which can create more relevant, meaningful, and valid results (Troya et al. 2019; Stevenson \& Taylor, 2019; Nind, 2011). Best 
et al., (2019) suggested that PTE was an accessible way to include less experienced co-researchers in qualitative data analysis. PTE helps address the limitations of participatory analysis by reducing the complexities of the time-consuming processes often involved in data analysis.

\section{Aims and Objectives}

\section{Aim}

The aim of this study is to present educational co-researchers analysis of qualitative data collected from focus groups with students and interviews with teachers.

\section{Objectives}

The objectives of this study are to:

(1) Investigate student and teachers' perspectives of adolescent mental health in schools.

(2) Identify suitable components for developing an intervention.

(3) Examine the use of PTE with teachers in the school setting.

(4) Examine the benefits of co-researcher data analysis

\section{Materials and Methods}

The methods described within this article focus on the PTE analysis only, though a brief comparison to the researcherled thematic analysis (Braun \& Clarke, 2006) is presented within the discussion section.

\section{Study Context}

The study adopted an exploratory qualitative research design which is recommended in the early intervention development stages (Morgan et al., 2016; Craig et al., 2008). This flexible path of inquiry provided richer information to help establish a more in-depth understanding of the research problem and programme development. The methods used during each stage of data collection allowed for an integration of the available evidence with stakeholder knowledge. The key stakeholders in the development process were researchers from Queen's University Belfast alongside staff and students from Royal Belfast Academical Institution, an all-male independent grammar school with over 1000 students aged 11-18 years old. This school was invited to be involved as the educational co-research partner to co-produce the intervention programme having expressed interest in developing programmes in relation to mental well-being. Co-production of the intervention involved a six step approach; (1) evidence review, (2) problem identification and joint analysis, (3) co-production of intervention prototype, (4) co-delivery (5) modification of intervention and (6) programme feasibility and refinement. The PTE analysis discussed in this paper was conducted within step two of this process.

The reason for this partnership stemmed from the importance of including key stakeholders in the development of complex interventions. Establishing a relationship and network with this local school could help create an effective working partnership which could provide a significant contribution to the research process (O'Mara \& Gutierrez, 2010; Horne \& Shirley, 2009). The engagement of these stakeholders can be instrumental in helping promote positive mental health and well-being within the school setting (Daly-Smith et al. 2020; Khan 2016). In addition, this process is mutually beneficial for the co-researchers as they can help create a programme and resource that may be valuable and effective for their school while providing them with the guidance to support adolescent mental health in schools (Time to Change 2012).

The qualitative data used in the current study was gathered within the post primary school setting and was collected as part of a larger three year Doctoral research programme. This data was procured from semi-structured interviews with teachers $(n=7)$ and focus groups $(n=6)$ with students from a larger doctoral study (Supplementary File 1). The audio recordings were transcribed verbatim and then coded to ensure participant anonymity. Details regarding the thematic analysis of the entire dataset can be found elsewhere [under preparation]. Ethical approval was gained from the School of Social Sciences, Education and Social Work at Queen's University Belfast (12th March 2018 and 7th November 2019; Ref no: 005_1920).

\section{Sample and Recruitment}

A convenience sample approach (Cohen, Manion, \& Morrison, 2017) was used to recruit the co-researchers from the post-primary setting who had no prior knowledge of the interview or focus group questions. The decision to use only teacher was due to time availability and students undergoing academic assessments. Recruitment was achieved through the network of key stakeholders (principal, school well-being coordinator, senior teachers) established through the co-production process highlighted within the study context. The teachers selected as co-researchers to undertake PTE were identified for their roles within the senior leadership team, experience of school's personal development programmes, and different curriculum areas. Six teachers were recruited to be involved in the PTE analysis process with five males and 
one female ages $30-50$ years old taking part. Consent was obtained before the research commenced.

\section{Data Collection and Analysis}

PTE was conducted through an accessible, five step approach (Table 1) outlined by Best et al. $(2017,2019)$, (1) data selection, (2) capacity building, (3) data sorting, (4) data grouping and (5) data analysis and interpretation. The PTE method (Table 1) required co-researchers' involvement in Steps two, three and five with the researcher (RN) responsible for steps one and four. Additionally, formal (questionnaire) and informal feedback (personal communication) were collected from the coresearchers to review the process of PTE.

\section{Data Selection}

The audio recordings of the teacher interviews and student focus groups from the main qualitative study were transcribed verbatim. One member of the academic research team (RN) initially read each transcript and selected excerpts that could be easily used as stand-alone statements for data analysis. The selected excerpts from the interview and focus group transcripts were then checked and verified by a second researcher (PB). No formal coding took place during this step and 60 quote excerpts were produced (Supplementary File 2). All statements were re-checked and anonymised before being presented to the co-researchers. The decision behind the selection of 60 excerpts was based on a number of factors, specifically repetition within excerpts and time available for teachers to participate in the data analysis process.

\section{Capacity Building}

In step two, the academic research team provided the coresearchers with an overview of the research project, PTE, and instructions on sorting data. In order to build capacity for the stakeholders to engage in the analysis process, the research team met with the co-researchers on two occasions. Each meeting lasted between 10 and $60 \mathrm{~min}$ and included discussions covering; (1) an overview of co-production in research, (2) the importance of school-based interventions, (3) adolescent mental health, (4) an overview of the research process, and (5) an overview of the PTE process and sorting techniques. By increasing the partners' knowledge in each of these areas, the aim was to provide them with new knowledge which would help guide decision making during the analysis and interpretation step.

\section{Data Sorting}

The 60 excerpts were given to the co-researchers, with each $(n=5)$ receiving one information folder containing an overview of the PTE process and sorting techniques, pens, post-its and the printed excerpt strips individually labelled 1-60. These co-researchers worked independently over a 40-min period, initially spending time reading to familiarise themselves with the data and without discussing their theme choices. The co-researchers were instructed to organise initial codes based on the general goal of developing a school-based mental health intervention. They were then instructed to sift through the excerpts and sort the statements into groups based on similar themes of their own choosing (Rosenberg, 2014; Coxon, 1999; Rosenberg \& Kim, 1975). No further instructions were given by the research team, as Garfield et al. (2016) acknowledged this could influence analysis of the data and therefore less instructions would be more beneficial in bringing out unique perspectives from the co-researchers. A member of the research team was available to answer any questions that arose from the partners' data

Table 1 Overview of the PTE analysis process

\begin{tabular}{|c|c|c|c|c|}
\hline Step 1 & Step 2 & Step 3 & Step 4 & Step 5 \\
\hline Data Selection & Capacity Building & Data Sorting & Data grouping & $\begin{array}{l}\text { Data Analysis and Interpreta- } \\
\text { tion }\end{array}$ \\
\hline \multicolumn{5}{|l|}{ Five step process for PTE } \\
\hline $\begin{array}{l}\text { Selection of quote excerpts } \\
\text { from qualitative data }\end{array}$ & Training of co-researchers & $\begin{array}{l}\text { Sorting quotes into piles and } \\
\text { themes }\end{array}$ & Network analysis & $\begin{array}{l}\text { Group discussion and review } \\
\text { of themes }\end{array}$ \\
\hline $\begin{array}{l}\text { Time taken to complete*: } \\
2 \mathrm{hrs}\end{array}$ & $\begin{array}{l}\text { Time taken to complete: } 1 \mathrm{hr} \\
40 \mathrm{~min}\end{array}$ & $\begin{array}{l}\text { Time taken to complete: } \\
40 \mathrm{~min}\end{array}$ & $\begin{array}{l}\text { Time taken to } \\
\text { complete: } \\
10 \text { min }\end{array}$ & Time taken to complete: $1 \mathrm{~h}$ \\
\hline
\end{tabular}

*The time taken to complete presented in the table is only representative of this current project and may be different in future research 
sorting or questions on the research process. After completion of the sorting process, each co-researcher had between five and ten groups for the excerpts, which were labelled and then stapled together (Fig. 1).

\section{Data Grouping}

The objective of step 4 was to construct a set of groups of excerpts that reflect the general consensus between the co-researchers' themes identified in step 3: Data Sorting. The groups organised by each co-researcher were labelled numerically and uploaded into a Microsoft Excel spreadsheet. Three columns were utilised to distinguish (1) Topic (Excerpt ID), (2) Person (Partner ID) and (3) Group. For example, if co-researcher 1 grouped excerpts 1, 6 and 40 together into the same theme, then this would be assigned a group ID for example, Grp1. This process continued until all excerpts had been labelled into numerical groups. The excel file was uploaded to online software created by Queen's University Belfast (Badham, Carton, Hunter, \& Best, 2019) for network analysis. This analysis first creates a network of quotes, assigning edge weights from the number of researchers who paired the quotes in the same pile (Best et al., 2019). The individual sorts are combined by applying a community detected algorithm to the weighted network that tries to keep together the most common combinations in the individual sorts (Blondel, Guillaume, Lambiotte, \& Lefebvre, 2008). The network of excerpts produced four core groupings (Fig. 2) with the thickness of the edge indicating the number of co-researchers who sorted the pair of excerpts into the same pile. The colour indicates groups identified in step 3: Group 1 (light blue), Group 2 (green), Group 3 (light pink) and Group 4 (red).

\section{Data Analysis and Interpretation}

Approximately a month after the data sorting took place, the network diagram along with the quotes within each group was presented to the co-researchers. All six co-researchers were able to attend. The network analysis diagram from step four was used to help stimulate discussion on the identified themes between the research team and co-researchers. Informed by the principles of Braun and Clarke's (2006) thematic analysis processes were then applied to explore the initial groups from the network analysis and interpret possible meanings. Themes and initial codes were recorded during the session with several quotes being reassigned to different groupings after discussions. The reassigned of quotes into other themes was expected as part of the iterative and collaborative process that is a feature of both PTE analysis and the co-production process.

\section{Results}

\section{Findings from PTE Analysis to Inform Intervention Development}

Four core themes were identified by the co-researchers through the PTE approach. These included (1) physical activity as a stress reliever, (2) programme facilitation, (3) exam pressure and (4) solutions to improve negative mental health.

\section{Physical Activity as a Stress Reliever}

The co-researchers identified a theme from the qualitative data that identified the role of physical activity in reducing stress and anxiety. This theme had three subthemes (a)

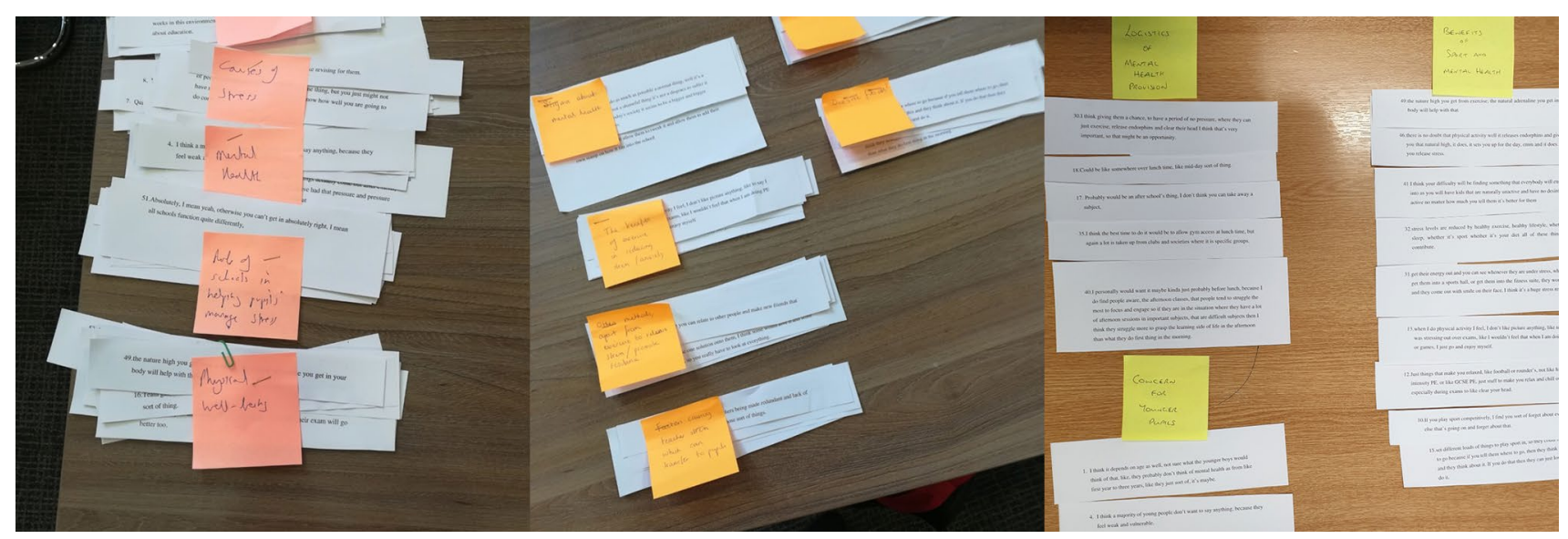

Fig. 1 Completed groups after step three 
Fig. 2 Network analysis diagram

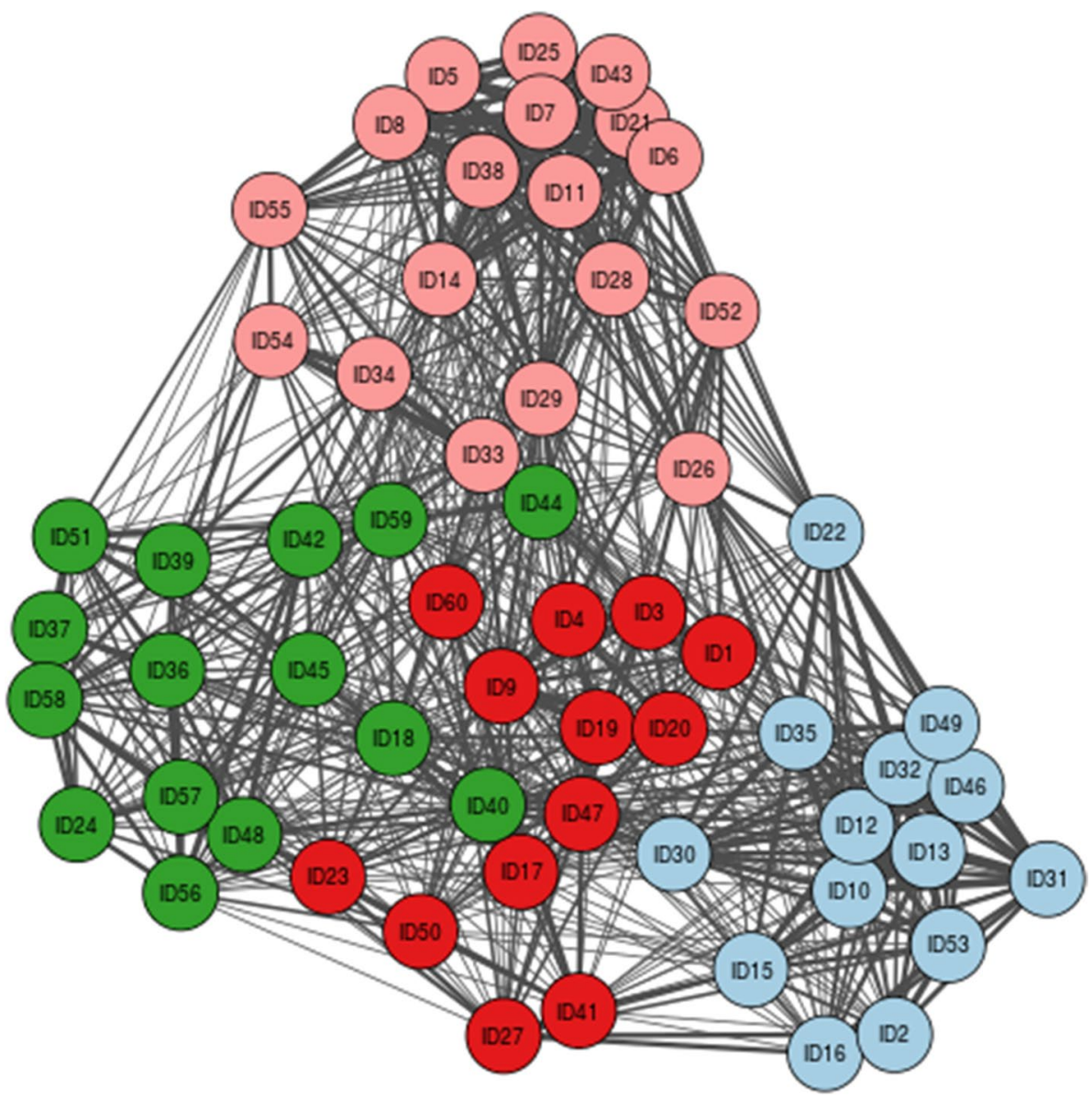

reducing stress to promote mental health and well-being, (b) social inclusion and (c) ability/possibilities to clear mind. The first sub-theme related mostly to the positive impact physical activity can have on individuals, such as the natural high that can be achieved. For example, several excerpts stated; "There is no doubt that physical activity, well it releases endorphins and gives you that natural high, it does, it sets you up for the day, emm and it does help you release stress" [ID46] and "get their energy out and you can see whenever they are under stress, when you get them into a sports hall, or get them into a fitness suite, they work hard and they come out with a smile of their face, I think it's a huge stress reliever" [ID31].

Data indicated that physical activity could promote "social inclusion/support" which the co-researchers suggested could be used as a core component within the intervention design. The interview and focus group data suggested that peer interaction would provide adolescents with an opportunity to get support with one individual noting; "they feel that especially within team sports, they find they have support from players and friends around them..." [ID53].

The role of relationships through physical activity was identified as important in adolescent mental health and therefore creating positive social networks could be important as an intervention component. One excerpt read; "team games, so you are like interacting with people and talking to people gets your mind off it" [ID3].

The final sub-theme was identified as "ability/possibilities to clear mind". Originally the co-researchers related this theme to physical activity as a stress reliever, however following an in-depth conversation, the group decided to recode this subtheme as they surmised that several excerpts were more strongly linked to one's mind-set. Two excerpts read, "I think giving them a chance, to have a period of no pressure, where they can just exercise, release endorphins and clear their head, I think that's very important, so that might be an opportunity" [ID30] and "Just things that make you relaxed like football or rounders, not like high intensity PE or like GCSE PE, just stuff to make you relax and chill out like especially during exams to like clear your head" [ID12]. An interesting element of this analysis is that the co-researchers debated the theme until they broke it down into sub-themes to highlight the importance of some level of physical activity as an intervention component. This suggests that the co-researcher team gained a new understanding of the data, progressing from a semantic approach reading the data to a more latent approach in their analysis (Braun 
\& Clarke, 2006, 2013). The co-researchers built on the initial ideas generated and became fully immersed in the data which allowed for a more in-depth and detailed thematic analysis which will be important in developing a sustainable school-based intervention. ID35 was reassigned to group 2 as this excerpt was highlighted by the co-researchers as a barrier to programme implementation.

\section{Programme Facilitation}

The co-researchers discussed that uncovering the theme of "programme facilitation" highlighted the difficulty in categorising mental health. The team suggested that the complexity of mental health means that one solution alone may not be the answer, which was also suggested within the academic literature which indicates that multi-modal interventions could be more effective (Putwain, Chamberlain, Daly, \& Sadreddini, 2014; Durlak et al., 2011). The coresearchers reported that multiple factors are required to deal with adolescent mental health issues in schools while citing that adolescents and future programme facilitators required tools to promote effective learning and creating a positive environment. However, it was highlighted that the intervention development process may be difficult as many different components and factors must be considered. This theme had four sub-themes (1) time and resources, (2) collaboration for programme facilitation and education, (3) sufficient practice is required and (4) requirement of differentiation within the programme.

The first sub-theme related mostly to the issue of time, particularly the limited time schools possess to implement programmes outside the curriculum. For example, "I think your biggest problem is the curricular time as we are already pressured with the amount of subjects you have to cover in those periods, you have to cover the specifications and get them done in time" [ID33] and "in schools, teachers are more and more stressed because of the deadlines they have to hit and the paperwork they have to do and adding that it would be your issues, finding time for it" [ID34]. Additionally, the PTE process with the co-researchers identified that selecting class groups or identifying the right target group could be problematic in programme implementation and facilitation, therefore age is a crucial factor to consider. One excerpt read; "how you fit that into the day, into timetables that are already quite difficult to manage and then how do you assign you know what year groups you're going to put that, or who is struggling the most..." [ID39].

While time constitutes a significant issue in the facilitation of programme development and delivery, the data stressed that a programme could be feasible if delivered over part of the lunch period; "I personally would want it maybe kinda around lunch, because I do find people aware, that the afternoon classes, that people tend to struggle the most and engage..." [ID40] and "I think the best time would be to allow gym access at lunch time..." [ID35]. Furthermore, one statement from the qualitative data recommended that a programme be implemented around examination periods; "we all become anxious at certain points, and there will be boys who become anxious around the time of exams" [ID43]. The qualitative data also indicated that financial resources could play an important role in schools facilitating mental health programmes; "...teachers being made redundant and the lack of funding and money and just all those sorts of things" [ID54]. This highlights that a short and cost-effective programme should be considered during the intervention development process.

The next identified sub-theme "Collaboration for programme facilitation and education" was similar to the academic literature which states that interventions should be developed with key stakeholders and the target population to create more cost-effective and sustainable solutions (Miller and Wyborn, 2018; Hawkins et al., 2017). Qualitative data revealed that schools needed to be educated on how mental health programmes can be delivered; "gotta get academic involvement and then we are going to have to educate down to this is why we are doing it and if we can do that then there is a chance" [ID57] and "you have to educate schools into what is right for their pupils" [ID58]. The analysis demonstrated that it is important for outside organisations to work with schools to help facilitate programme development; "an oversight role can say this works, this works in this environment or this works in all environments and then it's about education" [ID59] and "I think the key thing is for universities to come in and say here is a model that has worked, I think you sort of need to trial that....Here is all the resources you need, here is what works best and then still allow them to tweak it and allow them to add their own stamp on how it fits into the school" [ID56].

It was discussed that embedding researchers into the school environment is important for programme facilitation as this type of immersion in the school environment offers a deeper level of understanding: "I think if you had a man in a suit come and visit and say this is what you should do, and have a one template fit all, I don't think that does work, emm but for someone like you who has been here over a period of time and you have seen how things are, I think that works better. [ID48]." This highlights how important research co-production with schools can be in the development of complex interventions.

Another sub-theme highlighted was that "sufficient practice is required". The data referred to implementing a programme to a younger target population so that they begin to learn different coping mechanisms and develop new knowledge. One interviewee reported; "Yeah, they do, yeah, yeah and hopefully by the time they get to year 11, they have had sufficient practice at years 8,9 and 10, to allow them to do 
that, so by the time they get to year 11 they should know how to manage their time, and that's what they should do" [ID45]. This subtheme is broadly similar to literature which suggests that early intervention builds greater resilience to reduce the prevalence of severe mental health issues particularly in adulthood (World Health Organisation, 2019; Khan, 2016).

The final sub-theme of the group was categorised as the "requirement of differentiation within the programme." Data indicated that one approach will not be suitable to engage everyone; "trying to get differentiation in your lessons is one key thing, trying to get everybody involved without saying this is the weaker group or without having somebody overpowered in a game" [ID36] and "obviously depends on the child...some children thrive on competition and being in that competition environment that is their release and some children it is about burning energy and individual stuff, I think children are so individual and what they like to do is so individual so if you tried to impose one solution onto them, I think some would love it and some would hate it, so you really have to look at everything" [ID60]. This suggested that in designing the intervention, the programme must be inclusive and adaptable while structured to fit into the school environment. One excerpt read; 'Yeah because if you're not testing that you don't know where you pros and cons are and at least if your testing something that is live, you can adapt it and evaluate it and make the changes that are necessary" [ID42]. Within this grouping during the interpretation stage, the co-researchers re-assigned ID44 to Group 4 as it was suggested the excerpt did not fit into the theme programme facilitation.

\section{Exam Pressure}

This theme was discussed by co-researchers as an important factor in the school environment. The co-researchers unanimously agreed that a majority of the excerpts within group 3 were interlinked with the key factor being examinations. The qualitative data highlighted that exams had a major influence on adolescent mental health and resulted in increased anxiety and stress levels with excerpts highlighting how nervous and pressurised these young adolescents felt. One excerpt noted "well in terms of a kid's perspective, I just think of exams straight away... it's a big thing the exams and the pressure..." [ID25]. The pressure of school exams was linked to the pressure that individuals place on themselves during this time and the possibilities of examinations influencing their future; "exams decide what you're going to do with the rest of your life, if you're going to be successful or not" [ID6]; "quite a lot pressure to do well and revise" [ID7] and "...like where there is pressure on you to perform and for yourself" [ID8]. The co-researchers acknowledged that exams play an important role on student mental health and this was an important element to incorporate into an intervention. Notably, the co-researchers moved excerpts initially placed within this group during the network analysis process. ID29 was reassigned to group 4, ID33, ID34, ID43, ID54 were reassigned to group 2 as they fitted better with the theme identified.

\section{Solutions to Improve Negative Mental Health}

The final core theme, consisted of three sub-themes (1) Communication, (2) Education and (3) Pupil voice. The initial discussions for group 4 between the co-researchers noted that a number of the excerpts in this section should be re-assigned as they fitted in better to themes identified in other groups. ID3 and ID27 was reassigned to Group one's identified theme, physical activity as a stress reliever being allocated within the sub-theme, social inclusion. Five excerpts [ID1, ID17, ID41, ID47 and ID60] where reassigned to Group 2 as the co-researchers emphasised that these statements were more closely associated to programme facilitation that solutions.

One focus group excerpt highlighted that a number of adolescent males do not feel comfortable discussing mental health issues; "I think a majority of young people, don't want to say anything, because they feel weak and vulnerable" [ID4]. Therefore, it was apparent to the co-researchers that communication was a key solution in improving negative mental health. The data discussed that being able to communicate with peers or someone they trust could help reduce mental health issues; "a problem shared is a problem halved" [ID19] and "you should always like speak to someone you trust" [ID20]. By facilitating mental health discussions this could encourage more young males to discuss their mental health while outlining that mental health is a normal process and that everyone can be affected. For example, "I think being more open to letting people talk about it in school" [ID9].

The sub-theme of communication is strongly linked to education, as educating students and teachers in mental health issues can create open discussions and the transfer of knowledge which can facilitate the development of coping strategies. The data noted "yeah probably education across society would be a big thing and I suppose treatment is always the big thing...because you can't put your finger on an actual physical problem, it's hard because everyone is different, I suppose education is first" [ID50]. Additionally, the co-researchers reported that the data indicated that educating students about time management and coping strategies could be a key strategy to reduce mental health issues, for example; "it's how did they manage their time, how did they cope with stress, how do they cope with stressful situations" [ID44]. 
Co-researchers discussed that the data indicated how important it was to give the students a voice when developing the programme and taking their suggestions on board within the design. This was reported in the transcripts; "they could choose where to go because if you tell them where to go, then they think I have to do this, and they think about it. If you do that then they can just lose themselves and do it" [ID23]. The background and expertise of the co-researchers suggested that allowing the pupils to have a voice may create more engagement and help facilitate programme implementation and in the long-term reduce mental health issues.

\section{Co-Researcher Feedback on PTE Analysis Process}

Informal feedback conducted after the sorting task and the discussion phase of the PTE process, suggested that the tasks were easy to understand and that the training provided was very good and made the process easier. Additionally, formal (questionnaire) and informal feedback (personal communication) indicated that the co-researchers agreed that the amount and length of the excerpts were just the right length and indicated that any more would have made the task more challenging with the already restricted time they had available for the tasks. This highlights that PTE can be conducted within the school setting for a short period of time during the school day. The co-researchers found the process interesting and believed it provided a good opportunity to discuss different ideas and gain new perspectives from colleagues. One co-researcher reported that the network analysis diagram allowed the triangulation of responses which made the process easier to comprehend and explain the links between the themes. The questionnaire data indicated that all co-researchers appreciated the PTE process as it allowed them the opportunity to interact with their colleagues in a different way and gain new perspectives on major issues affecting students in the school setting.

Teachers outlined that the use of 60 short and easy to interpret excerpts made this process accessible for the teachers as co-researchers as it allowed data analysis to be conducted over a short time period that suited their schedules. Informal feedback suggested that the use of the network diagram facilitated conversation between the group, and it allowed for a more in-depth analysis of the excerpts. This suggests that PTE is an acceptable method to analyse data with lay researchers (teachers) in the school setting. Best et al. (Best et al. 2017, p. 10) outlined that the purpose of PTE is to provide a "robust, accessible and reproducible approach" to involve lay-researchers within a meaningful coproduction process in regard to data analysis. An important finding from this paper highlights that PTE is an accessible method which can easily be reproduced in a different context and still produce valid results.

\section{Discussion}

Using co-researchers to analyse data, the aim of this study was to explore findings from the PTE to investigate the views of students and teachers as to what factors need to be considered in the development of a school-based mental health intervention. The results suggested that exam anxiety should be explored as a key outcome for the focus of a school mental health intervention. This supports recent research which highlighted that exam anxiety is a major mental challenge for adolescents with approximately 10-40 percent being severely affected by this issue (von der Embse, Jester, Roy, \& Post, 2018; Thomas, Cassady, \& Finch, 2018; Putwain et al., 2014). Qualitative data also confirmed that mental health is a complex area to examine and therefore multiple components are required in implementing solutions to improve mental health outcomes like stress and anxiety. Therefore, a multi-component programme design is seen as more effective, particularly in the school setting (Putwain et al., 2014; Durlak et al., 2011) and should be considered in future intervention development.

Supporting previous literature (Gartlehner et al., 2017; McDowell, MacDonncha, \& Herring, 2017; McMahon et al., 2017) the findings recommended that incorporating physical activity into an intervention, provides a novel way to facilitate discussion on mental health as it can be used as a stress reliever during examination periods. This was evidenced through positive comments within the qualitative transcripts on how social inclusion and the ability to clear one's mind through physical activity could be highly beneficial. Education and communication were noted as ways to increase adolescent knowledge on mental health while normalising discussing these issues. These findings again suggest that a multi-component intervention is required to help combat exam anxiety and promote wellbeing in schools to help adolescents develop coping strategies to overcome or reduce these challenges.

Programme facilitation discussed within the qualitative data, outlined several barriers to programme implementation such as time and financial resources. Bowen, Jenson, and Clark (2003) stated that the running time of an intervention is crucial as the timing of each session can impact on the sustainability and effectiveness of the programme. Additionally, similar to the co-research findings, evidence suggests that schools do not have access to appropriate resources, which can be problematic within programme implementation (Wight, Wimbush, Jepson, \& Doi, 2016; Time to Change, 2012). These barriers highlight that due to curriculum demands and financial resources, a short cost-effective programme is a necessity that does not place any further time limitations or pressures on the school. 
Furthermore, the data suggested that collaboration is important factor to consider in intervention facilitation and development so that the programme can be tailored appropriately to the research context and address key issues. This context and information provided by the key stakeholders can help support intervention development to create a programme that is valuable and can be implemented to overcome barriers that the co-researchers acknowledged. Van Nassau et al. (2016) argued that shared decision making with others is a facilitating factor in intervention development with evidence demonstrated that project buy in through this co-design process is an appropriate approach to take (Hawkins et al., 2017; Campbell \& Vanderhoven, 2016). This indicates that research co-production can only benefit the development of complex interventions by identifying the problem in which the programme should explore and providing essential information that can create meaningful and innovative solutions to deal with these mental health issues in schools.

The results generated from the co-researcher's PTE analysis were similar to the researcher's thematic analysis of the interview and focus group transcripts. A brief summary of themes is outlined in Table 2. More detailed findings from the academic researcher's analysis will be presented separately (in preparation). The additional sub-themes within each analysis process, while using different terminology, closely generated similar themes. This suggests proves that PTE can be a useful approach in producing meaningful results while confirming the researchers' findings. The similarities highlight that PTE can be an innovative and acceptable process for analysing qualitative data and increasing the overall validity of the research findings. Furthermore, it demonstrates that the PTE process is also acceptable to be used with teachers in the school setting.

While there were numerous similarities between the researcher's thematic analysis and the PTE analysis undertaken by the co-researchers, there was one difference across the findings. From the data, the researcher identified a suitable target age from the qualitative data which the coresearcher team did not uncover. This contrast between the researcher's analysis and co-researchers' analysis may have occurred due to the co-researchers lack of experience and knowledge of the research process and thematic analysis for intervention development. Future collaboration with co-researchers should provide the researcher with a more indepth understanding of the factors affecting any programmes designed in schools.

Overall, the findings from this study suggest that PTE is an acceptable method to engage co-researchers in participatory data analysis and is an effective and valuable approach to analyse data with lay researchers in the school setting. Best et al. (2017, p.10) outlined that the purpose of PTE is to provide a "robust, accessible and reproducible approach" to involve lay-researchers within a meaningful co-production process in regard to data analysis. An important finding from this paper highlights that PTE is an accessible method which can be replicated in different contexts to produce valid results that can contribute to intervention development.

The valuable input from the co-researchers during the data analysis and discussion phase of PTE provided new knowledge which contributed to the development of a school-based intervention which was part of the aim of this bigger research project. The PTE process with the coresearchers provided a more in-depth understanding and explanation of the complexity of the school environment which may not have surfaced without this valuable input from the key stakeholders and PTE process. The insider perspective aided the study findings and, alongside the researcher's thematic analysis of the transcripts, led to the co-production of the R.E.A.C.T. (Reducing Exam-Anxiety through Activity and Coping Techniques) programme, a 6-week school-based intervention for adolescents aged 12-14 years old. These findings from the PTE analysis carried out by the co-researchers greatly contributed to the development of the R.E.A.C.T. programme and suggests that the PTE process may be more effective than other methods.

\section{Strengths and Limitations}

A unique aspect of this study was the involvement of school stakeholders in the analysis of qualitative data through PTE. The use of co-researchers who are present in the school setting on a daily basis was a major strength of the study as was having co-researchers from different academic backgrounds and fields during the analysis phase of PTE. PTE analysis has previously not been conducted within the school setting and therefore it is important to consider school stakeholders as co-researchers particularly
Table 2 Comparison of co-researchers PTE themes v researcher-led thematic analysis themes

\begin{tabular}{ll}
\hline Co-researchers PTE analysis & Researcher-led thematic analysis \\
\hline Physical activity as a stress reliever & Mental health \\
Exam Pressure & Test Anxiety \\
Solutions to negative mental health & Ways to reduce anxiety and stress \\
Programme facilitation & Facilitators for intervention development \\
& Barriers to intervention implementation \\
\hline
\end{tabular}


within data analysis to create an efficient school-based intervention. The findings of this study indicated that using teachers as co-researchers in the data analysis can be a valuable process for intervention development in the school setting. These individuals provided an insider knowledge and expertise of the school environment and adolescent mental health issues which was crucial in identifying core themes and will be essential in the transfer of knowledge required to develop a school-based intervention in the next phase of the research co-production process. This was a perspective that the research team did not have and this transfer of knowledge was beneficial in creating new links between codes that the research team may not have been able to establish. Furthermore, all co-researchers were present for both step three-sorting task and step five-data analysis and interpretation. As part of the co-production process for intervention development involving the co-researchers in the data analysis process increases the quality of the analysis and results while improving on the past limitations of the process in which the co-researcher's involvement was generally only tokenistic and focused on coding the data (Cowley, Kerr, Darby, \& Logan, 2019; Garfield et al., 2016; Stevenson, 2014; Foster et al., 2012; Nind, 2011).

There are some limitations within this study which will be identified for future research. Co-researchers were only selected from one school which was involved in the research process as a partner school in co-producing the intervention. A criticism of using this convenience sampling technique is that it increases vulnerability to selection bias and influences beyond the researchers control (Cohen et al., 2017; Bryman, 2016) which can be limiting for the research process.

Furthermore, teachers were only recruited as co-researchers for the data analysis process, therefore, not including students in the data analysis process was another limitation, as this may have introduced a different insight into the qualitative analysis. Only 60 excerpts were selected from interview and focus group transcripts of a larger qualitative study and therefore did not include the observational data collected from three schools which limits the information available for the co-researchers to analyse. However, due to time restrictions in the school setting it was only feasible for teachers to analyse this specific number of quotes. The primary researcher (RN) was involved in both the qualitative data collection and selection of excerpts for the coresearchers, which introduces the possibility of selection bias. To reduce the risk of this influencing the findings, a member of the research team, not involved in data collection, should select the excerpts. In the current study, the selected excerpts were checked and verified by a second researcher (PB) which reduce the risk of bias.

\section{Conclusion}

This paper has attempted to go beyond the normal process for co-production and involving stakeholders in the analysis of qualitative data. The findings demonstrated that anxiety around examinations is a major problem in schools and identified facilitators and barriers for intervention development. The involvement of teachers as co-researchers in the PTE analysis process provided a perspective outside that of the research team which established more meaningful findings. However, given that only one school was used and the small number of educational co-researchers in the process, the conclusions should be viewed tentatively. Future work using the PTE method should increase the number of co-researchers from not just the school environment but from different backgrounds, e.g. community groups or mental health organisations. Additionally, the co-researchers only examined 60 quote excerpts which was a small selection from a larger dataset and may not have been representative of the full dataset. Future research using the PTE approach in the school setting would benefit from trialling out larger numbers of quotes to determine acceptability.

Supplementary Information The online version contains supplementary material available at https://doi.org/10.1007/s12310-021-09418-w.

Acknowledgements The authors would like to thank the co-research team for their time and input in this research project. We would also like to thank the students and teachers for participating in the interviews and focus groups. The authors would like to acknowledge Jade Yap for her contribution to this paper.

Funding The preparation of this review was made possible through a $\mathrm{PhD}$ scholarship grant from the Department for the Economy.

\section{Compliance with Ethical Standards}

Conflict of interest The authors declare that they have no competing interests to disclose.

Ethical Approval Ethical approval was received from the School of Social Sciences, Education and Social Work, Queen's University Belfast.

Open Access This article is licensed under a Creative Commons Attribution 4.0 International License, which permits use, sharing, adaptation, distribution and reproduction in any medium or format, as long as you give appropriate credit to the original author(s) and the source, provide a link to the Creative Commons licence, and indicate if changes were made. The images or other third party material in this article are included in the article's Creative Commons licence, unless indicated otherwise in a credit line to the material. If material is not included in the article's Creative Commons licence and your intended use is not permitted by statutory regulation or exceeds the permitted use, you will need to obtain permission directly from the copyright holder. To view a copy of this licence, visit http://creativecommons.org/licenses/by/4.0/. 


\section{References}

Arnold, J., Bruce-Low, S., Henderson, S., \& Davies, J. (2016). Mapping and evaluation of physical activity interventions for schoolaged children. Public Health, 136, 75-79.

Badham, J, Carton, J., Hunter, R., Best, P. (2019). Participatory Theme Elicitation. Queens University Belfast. Retrieved 2019, from https ://jbadham.shinyapps.io/PTEbasic/.

Best, P., Badham, J., Corepal, R., O’Neill, R. F., Tully, M. A., Kee, F. and Hunter, R. F. (2017). Network methods to support user involvement in qualitative data analyses: An introduction to participatory theme elicitation. Trials, 18(559).

Best, P., McConnell, T., Davidson, G., Badham, J., \& Neill, R. D. (2019). Group based video-conferencing for adults with depression: Findings from a user-led qualitative data analysis using participatory theme elicitation. Research Involvement and Engagement, 5(1), 40 .

Biddle, S. J. H., Mutrie, N., \& Gorely, T. (2015). Psychology of Physical Activity: Determinants, Well-Being and Interventions (3rd ed.). London: Routledge.

Blondel, V. D., Guillaume, J. L., Lambiotte, R., \& Lefebvre, E. (2008). Fast unfolding of communities in large networks. Journal of Statistical Mechanics: Theory and Experiment, 2008(10), P10008.

Bowen, J., Jenson, W. R., \& Clark, E. (2003). School-Based Interventions for Students with Behavior Problems. New York: Kluwer Academic/Plenum Publishers.

Bradshaw, J., \& Keung, A. (2011). Subjective well-being and mental health. In J. Bradshaw (Ed.) The Well-being of Children in the UK, 3rd edition. (pp. 89-110). Bristol: The Press Policy.

Braun, V., \& Clarke, V. (2006). Using thematic analysis in psychology. Qualitative Research in Psychology, 3(2), 77-101.

Braun, V., \& Clarke, V. (2013). Successful qualitative research: A practical guide for beginners. Thousand Oaks: Sage.

Breslin, G., \& Brennan, D. (2012). A healthy lifestyle intervention delivered by aspiring physical education teachers to children from social disadvantage: study protocol and preliminary findings. Child Care in Practice, 18(3), 207-225.

Brown, C., \& Dixon, J. (2020). 'Push on through': Children's perspectives on the narratives of resilience in schools identified for intensive mental health promotion. British Educational Research Journal, 46(2), 379-398.

Bryman, A. (2016). Social research methods (5th ed.). Oxford: Oxford University Press.

Campbell, H., \& Vanderhoven, D. (2016). Knowledge that matters: realising the potential of co-production. Economic and Social Research Council and N8 Research Partnership, England

Clarke, D., Jones, F., Harris, R., \& Robert, G. (2017). What outcomes are associated with developing and implementing co-produced interventions in acute healthcare settings? A rapid evidence synthesis. British Medical Journal Open, 7(7), e014650.

Cohen, L., Manion, L., \& Morrison, K. (2017). Research Methods in Education. New York: Routledge.

Cowley, A., Kerr, M., Darby, J., \& Logan, P. (2019). Reflections on qualitative data analysis training for PPI partners and its implementation into practice. Research Involvement and Engagement, 5(1), 22.

Coxon, A. P. (1999). Sorting data: Collection and analysis. Thousand Oaks: Sage.

Craig, P., Dieppe, P., Macintyre, S., Michie, S., Nazareth, I., \& Petticrew, M. (2008). Developing and evaluating complex interventions: The new Medical Research Council guidance. BMJ, p. 337.

Daly-Smith, A., Quarmby, T., Archbold, V. S., Corrigan, N., Wilson, D., Resaland, G. K., et al. (2020). Using a multi-stakeholder experience-based design process to co-develop the Creating Active
Schools Framework. International Journal of Behavioral Nutrition and Physical Activity, 17(1), 13.

Das, J. K., Salam, R. A., Lassi, Z. S., Khan, M. N., Mahmood, W., Patel, V., \& Bhutta, Z. A. (2016). Interventions for adolescent mental health: An overview of systematic reviews. Journal of Adolescent Health, 59(4), S49-S60.

Durlak, J. A., Weissberg, R. P., Dymnicki, A. B., Taylor, R. D., \& Schellinger, K. B. (2011). The impact of enhancing students' social and emotional learning: A meta-analysis of school-based universal interventions. Child Development, 82(1), 405-432.

Eiland, L., \& Romeo, R. D. (2013). Stress and the developing adolescent brain. Neuroscience, 249, 162-171.

Erskine, H. E., Moffitt, T. E., Copeland, W. E., Costello, E. J., Ferrari, A. J., Patton, G., \& Scott, J. G. (2015). A heavy burden on young minds: The global burden of mental and substance use disorders in children and youth. Psychological Medicine, 45(7), 1551.

Foster, J. W., Chiang, F., Burgos, R. I., Cáceres, R. E., Tejada, C. M., Almonte, A. T., \& Heath, A. (2012). Community-based participatory research and the challenges of qualitative analysis enacted by lay, nurse, and academic researchers. Research in Nursing \& Health, 35(5), 550-559.

Garfield, S., Jheeta, S., Husson, F., Jacklin, A., Bischler, A., Norton, C., \& Franklin, B. D. (2016). Lay involvement in the analysis of qualitative data in health services research: A descriptive study. Research Involvement and Engagement, 2(1), 1-12.

Gartlehner, G., Wagner, G., Matyas, N., Titscher, V., Greimel, J., Lux, L., \& Lohr, K. N. (2017). Pharmacological and non-pharmacological treatments for major depressive disorder: Review of systematic reviews. British Medical Journal Open, 7(6), e014912.

Hawkins, J., Madden, K., Fletcher, A., Midgley, L., Grant, A., Cox, G., \& White, J. (2017). Development of a framework for the coproduction and prototyping of public health interventions. $B M C$ Public Health, 17(1), 689.

Holt, M.K., Greif Green J., \& Guzman, J. (2018). School Settings. In T.H. Ollendick, S.W., White, \& B.A. White (Eds.) The Oxford Handbook of Clinical Child and Adolescent Psychology (pp. 611-622). New York: Oxford University Press.

Hoover, S.A., \& Mayworm, A.M. (2007). The Benefits of School Mental Health. In K.D., Michael \& J.P., Jameson (Eds.) Handbook of Rural School Mental Health. (pp. 3-16).Cham: Springer.

Horne, M., \& Shirley, T. (2009). Co-Production in Public Services: A New Partnership with Citizens. London: Cabinet Office.

Jones, A. M., West, K. B., \& Suveg, C. (2019). Anxiety in the school setting: a framework for evidence-based practice. School Mental Health, 11(1), 4-14.

Khan, L. (2016). Missed Opportunities: A Review of Recent Evidence into Children and Young People's Mental Health. London: Centre for Mental Health.

King, C., \& Gillard, S. (2019). Bringing together coproduction and community participatory research approaches: Using first person reflective narrative to explore coproduction and community involvement in mental health research. Health Expectations, 22(4), 701-708

Lakes, K., Nguyen, H. M., Jones, M., \& Schuck, S. E. (2019). I am me: Adolescent perspectives of a school-based universal intervention program designed to promote emotional competence. International Journal of Emotional Education., 11(1), 97-114.

Lind, C. (2007). The power of adolescent voices: Co-researchers in mental health promotion. Educational Action Research, 15(3), 371-383.

McDowell, C. P., MacDonncha, C., \& Herring, M. P. (2017). Brief report: Associations of physical activity with anxiety and depression symptoms and status among adolescents. Journal of Adolescence, 55, 1-4.

McMahon, E. M., Corcoran, P., O’Regan, G., Keeley, H., Cannon, M., Carli, V., \& Balazs, J. (2017). Physical activity in European 
adolescents and associations with anxiety, depression and wellbeing. European Child \& Adolescent Psychiatry, 26(1), 111-122.

Mental Health Foundation. (2020). Children and young people. Retrieved from https://www.mentalhealth.org.uk/a-to-z/c/child ren-and-young-people.

Miller, C. A., \& Wyborn, C. (2018). Co-production in global sustainability: histories and theories. Environmental Science \& Policy.

Morgan, H., Thomson, G., Crossland, N., Dykes, F., \& Hoddinott, P. (2016). Combining PPI with qualitative research to engage 'harder-to-reach'populations: service user groups as co-applicants on a platform study for a trial. Research Involvement and Engagement, 2(1), 7.

Mulvaney-Day, N. E., Rappaport, N., Alegria, M., \& Codianne, L. M. (2006). Developing systems interventions in a school setting: An application of community-based participatory research for mental health. Ethnicity and Disease, 16(1), S1.

NICCY (2017). Child and Adolescent Mental Health in NI. Belfast: NICCY. Retrieved October 24, 2017, from http://www.niccy.org/ media/2810/niccy-scoping-paper-mental-health-review-apr-2017. pdf.

Nind, M. (2011). Participatory data analysis: A step too far? Qualitative Research, 11(4), 349-363.

O’Donnell, P. S., \& Dunlap, L. L. (2019). Teacher acceptability of progressive muscle relaxation in the classroom for the treatment of test anxiety. Journal of Psychologists and Counsellors in Schools, 29(2), 151-165.

O'Mara, J., \& Gutierrez, A. (2010). Classroom teachers as co-researchers: The affordances and challenges of collaboration. Australian Journal of Language and Literacy, 33(1), 41.

O'Reilly, M., Adams, S., Whiteman, N., Hughes, J., Reilly, P., \& Dogra, N. (2018). Whose responsibility is adolescent's mental health in the UK? Perspectives of key stakeholders. School Mental Health, 10(4), 450-461.

Pugh, G., \& Statham, J. (2006). Interventions in schools in UK. In P. Pecora \& W. Rose (Eds.), Enhancing the Well-being of Children and Families through Effective Interventions (pp. 276-288). London: Jessica Kinsley Publishers.

Putwain, D., Chamberlain, S., Daly, A. L., \& Sadreddini, S. (2014). Reducing test anxiety among school-aged adolescents: A field experiment. Educational Psychology in Practice, 30(4), 420-440.

Ribeiro, I. C., Parra, D. C., Hoehner, C. M., Soares, J., Torres, A., Pratt, M., et al. (2010). School-based physical education programs: Evidence-based physical activity interventions for youth in Latin America. Global Health Promotion., 17(2), 5-15.

Rosenberg, S. (2014). The method of sorting in multivariate research with applications selected from cognitive psychology and person perception. In N. Hirschberg \& L. G. Humphreys (Eds.), Multivariate Applications in the Social Sciences (pp. 123-148). New York: Psychology Press.

Rosenberg, S., \& Kim, M. P. (1975). The method of sorting as a datagathering procedure in multivariate research. Multivariate Behavioral Research, 10(4), 489-502.

Shalanski, L., \& Ewashen, C. (2019). An interpretive phenomenological study of recovering from mental illness: Teenage girls' portrayals of resilience. International Journal of Mental Health Nursing, 28(2), 492-500.

St Leger, L. (2001). Schools, health literacy and public health: Possibilities and challenges. Health Promotion International, 16(2), 197-205.

Stevenson, M. (2014). Participatory data analysis alongside coresearchers who have Down Syndrome. Journal of Applied Research in Intellectual Disabilities, 27(1), 23-33.
Stevenson, M., \& Taylor, B. J. (2019). Involving individuals with dementia as co-researchers in analysis of findings from a qualitative study. Dementia, 18(2), 701-712.

Sullivan, R. A., Kuzel, A. M. H., Vaandering, M. E., \& Chen, W. (2017). The association of physical activity and academic behavior: A systematic review. Journal of School Health, 87(5), 388-398.

Thomas, C. L., Cassady, J. C., \& Finch, W. H. (2018). Identifying severity standards on the cognitive test anxiety scale: Cut score determination using latent class and cluster analysis. Journal of Psychoeducational Assessment, 36(5), 492-508.

Time to Change. (2012). Children and young people's programme development. Summary of research and insights. Retrieved from https://www.time-to-change.org.uk/sites/default/files/TTC $\% 20$ CYP\%20Report\%20FINAL.pdf.

Troya, M. I., Chew-Graham, C. A., Babatunde, O., Bartlam, B., Higginbottom, A., \& Dikomitis, L. (2019). Patient and public involvement and engagement in a doctoral research project exploring self-harm in older adults. Health Expectations, 22(4), 617-631.

Væggemose, U., Ankersen, P. V., Aagaard, J., \& Burau, V. (2018). Coproduction of community mental health services: Organising the interplay between public services and civil society in Denmark. Health \& Social Care in the Community, 26(1), 122-130.

Van Nassau, F., Singh, A. S., Broekhuizen, D., Van Mechelen, W., Brug, J., \& Chinapaw, M. J. (2016). Barriers and facilitators to the nationwide dissemination of the Dutch school-based obesity prevention programme DOiT. The European Journal of Public Health, 26(4), 611-616.

von der Embse, N., Jester, D., Roy, D., \& Post, J. (2018). Test anxiety effects, predictors, and correlates: A 30-year meta-analytic review. Journal of Affective Disorders, 227, 483-493.

Weeks, C., Hill, V., \& Owen, C. (2017). Changing thoughts, changing practice: examining the delivery of a group CBT-based intervention in a school setting. Educational Psychology in Practice, $33(1), 1-15$.

Wight, D., Wimbush, E., Jepson, R., \& Doi, L. (2016). Six steps in quality intervention development (6SQuID). Journal of Epidemiology and Community Health, 70(5), 520-525.

World Health Organisation. (2012). Young and Physically Active: a blueprint for making physical activity appealing to youth. Retrieved from http://www.euro.who.int/_data/assets/pdf file/0005/175325/e96697.pdf.

World Health Organization (2019). Adolescent Mental Health. Retrieved from: https://www.who.int/news-room/fact-sheets/detai 1/adolescent-mental-health.

World Health Organization (2020). Adolescent health epidemiology. Retrieved from https://www.who.int/maternal_child_adolescent/ epidemiology/adolescence/en/who.int.

Yap, J., McCartan, C., Davidson, G., White, C., Bradley, L., Webb, P., $\&$ Best, P. (2020). An exercise intervention for people with serious mental illness: Findings from a qualitative data analysis using participatory theme elicitation. Health Expectations.

Publisher's Note Springer Nature remains neutral with regard to jurisdictional claims in published maps and institutional affiliations. 